\title{
COVID-19: a comparison to the 1918 influenza and how we can defeat it
}

\author{
Shu Ting Liang $(1),{ }^{1,2}$ Lin Ting Liang, ${ }^{1}$ Joseph M Rosen ${ }^{1,2}$
}

\section{INTRODUCTION}

This paper is dedicated to Andrew Price Smith for his extensive analysis of the impact of the 1918 influenza and for being the first to investigate the Austrian Spanish Influenza Archives to demonstrate that the virus struck the Axis troops prior to the Alliance, which forced Kaiser to opt for peace.

The COVID-19 pandemic has altered the lives of people around the world, with significant death toll in addition to global social, political and economic impact. Many people have wondered how it compares to the seasonal influenza and prior pandemics. In order to better understand and manage the current pandemic, it is useful to compare it to historical pandemics, such as the Spanish influenza of $1918 .^{1}$

\section{BRIEF HISTORICAL OVERVIEW OF 1918 SPANISH INFLUENZA}

The 1918 Spanish influenza is caused by an $\mathrm{H} 1 \mathrm{~N} 1$ influenza A virus postulated to be of avian origin. ${ }^{2}$ The 1918 Spanish influenza lasted from 1918 to 1920 and consisted of four waves. The first wave lasted approximately from 15 February 1918 to 1 June 1918; the second lasted approximately from 1 August 1918 to 2 December 1918; the third lasted approximately from 3 December 1918 to 30 April 1919; and the fourth wave lasted approximately from 1 December 1919 to 30 April 1920. ${ }^{3}$ It infected about 500 million people, roughly one-third of the world's population at that time, and resulted in the deaths of 50 million, including 675 000 Americans. $^{2}$ The first public news of the epidemic appeared in Madrid on 22 May 1918 in Madrid's ABC newspaper; hence, it became known as the Spanish influenza. ${ }^{4}$ However, there is no definite evidence of origination, and most epidemiologists and virologists believe that

\footnotetext{
'Dartmouth-Hitchcock Medical Center, Lebanon, New Hampshire, USA

${ }^{2}$ Department of Plastic Surgery, Geisel School of Medicine, Dartmouth College, Hanover, New Hampshire, USA
}

Correspondence to Shu Ting Liang, DartmouthHitchcock Medical Center, Lebanon, NH 03766, USA; shu.ting.liang.med@dartmouth.edu the virus originated in either the USA or France. ${ }^{4}$ A week later on 28 May 1918, King Alfonso XIII, the Prime Minister and some cabinet members became ill. ${ }^{4}$ As the influenza spread, basic services such as the postal service, telegraph services and some banks were forced to temporarily close operations. $^{4}$

\section{COMPARISON BETWEEN COVID-19 AND 1918 INFLUENZA}

First, the patient population differs. While the 1918 influenza killed a disproportionate number of 25-40 year olds, COVID-19 mostly affects those over the age of 65 , especially those also with comorbidities. ${ }^{2} 5$ In particular, the mortality rate for the influenza rose to $8 \%-10 \%$ for younger people compared with a $2.5 \%$ overall mortality whereas the mortality rate for the 25-40-year-old age range is a mere $0.2 \%$ in contrast to the $2.4 \%$ overall mortality rate. ${ }^{25}$ Those aged 25-40 year olds accounted for 40\% of deaths from the 1918 influenza, whereas those in the 18-44-year-old range account for only $3.9 \%$ of deaths from COVID$19 .^{2} 5$ More countries were spared in the 1918 pandemic, whereas only the smaller Pacific Islands (Soloman Islands and Vanuata) remain COVID-19 free. $^{2} 6$ The mortality rate for pregnant women with the Spanish influenza was 23\%-37\% and $26 \%$ of those who survived but lost their child, whereas the mortality rate of pregnant women with COVID-19 is unknown. ${ }^{2} 7$ The Spanish influenza resulted in acute illness in 25\%-30\% of the world population, with over 50 million deaths, whereas COVID-19 has infected nearly 55 million to date, with 1.3 million deaths. ${ }^{25}$ In the USA alone, COVID-19 cases are at over 11 million as of 16 November 2020, which is nearly a $40 \%$ increase from the month prior. ${ }^{5}$

Second, the two diseases kill via different mechanisms. While those with the influenza died of secondary bacterial pneumonia, those with COVID-19 died from an overactive immune response that resulted in multiple organ failure. ${ }^{28}$ Acute respiratory distress syndrome (ARDS) can develop in both cases. ${ }^{28}$ As a complication from the influenza, ARDS had an 100\% fatality rate compared with a 53.4\% mortality rate as a complication from COVID-19. ${ }^{29}$

The projected economic impact of COVID-19 on the US economy is a $\$ 5.76-$ $\$ 6.17$ trillion decrease in gross domestic product (GDP), based on Fitch Ratings and the US GDP according to the World Bank. The economic data during the 1918 pandemic is scarce, but it was noted that Mexico suffered a $\$ 9$ billion loss. ${ }^{2}$

Diagnoses, treatments and vaccines were delayed in both cases. States developed different COVID-19 diagnostic tests, since the initial one by Centers for Disease Control and Prevention (CDC) could not be confirmed. Currently, there are no COVID-19 treatments approved by the Food and Drug Administration, but antivirals like remdesivir, antibody and interleukin 33 blockers are currently under investigation. Vaccines are also in development. In 1918, bleeding was initially used as treatment, since such minimal progress had been made against pneumonia that even renowned William Osler still recommended it to relieve symptoms. $^{2}$ In 1917, Dr Rufus Cole, Dr Oswald Avery and Dr Alphonse Dochez, with help from six other Rockefeller researchers, developed and tested a vaccination to prevent pneumonia caused by types I, II and III pneumococci. In March 1918, this vaccine was given to 12000 troops on Long Island, with no vaccinated solder developing pneumonia from those strains. In contrast, 101 out of 19000 soldiers serving as controls, developed pneumonia from those strains. ${ }^{2}$

Yet, since neither an influenza vaccine nor antibiotics to treat associated secondary bacterial infections were available, worldwide containment efforts relied heavily on isolation and quarantine similar to the current efforts against COVID-19. ${ }^{2}$

In terms of duration and origination, there is controversy over the origination of both viruses, and both consist of multiple waves. The 1918 influenza lasted 25 months, and may have originated in Spain, France or the USA with no definite evidence of origination. ${ }^{34}$ The first wave lasted approximately from 15 February 1918 to 1 June 1918 and the fourth and final wave lasted approximately from 1 December 1919 to 30 April $1920 .{ }^{3}$ COVID-19 originated in Wuhan China on 31 December 2019, with controversy over whether it originated in a wet market or at the Wuhan Institute of Virology. Unlike in 1918, DNA sequencing of COVID-19 can predict whether infected individuals will be symptomatic or asymptomatic, based on a single base change $(11083 \mathrm{G}>\mathrm{T}) .{ }^{10}$ 
Table 1 Summary of major differences: COVID-19 versus 1918 influenza

\begin{tabular}{|c|c|c|}
\hline & COVID-19 & 1918 influenza \\
\hline Viral aetiology & SARS-CoV-2 & H1N1 influenza A virus \\
\hline Mortality rate & $2.40 \%$ & $2.50 \%$ \\
\hline Number of deaths & 2.2 million & 50 million \\
\hline Highest risk population & $65+$ with comorbidities & 25-40 year olds \\
\hline Cause of death & Overactive immune system leading to end organ failure & Secondary bacterial infection \\
\hline Place of origin & Wuhan (either in a wet market or Wuhan Institute of Virology) & Haskell County, Kansas \\
\hline Virus type & Coronavirus & Orthomyxoviridae \\
\hline Economic impact & $\$ 5.76$ trillion- $\$ 6.17$ trillion decrease in Gross Domestic Product (GDP) & Minimal economic data, Mexico suffered a $\$ 9$ billion loss \\
\hline
\end{tabular}

\section{CONCLUSIONS}

Both the COVID-19 and 1918 influenza pandemic similarly caused significant negative impacts on the global economy, affecting international relations and had considerable delay in its diagnosis, treatment and vaccines. The pandemics largely differed in the highest risk population and the mechanism of death. The 1918 influenza affected less than half of the countries and the most vulnerable groups are healthy adults between the ages of 25 years and 40 years, while COVID-19 has affected nearly all countries and the most vulnerable group are adults above 65 years of age with comorbidities. Victims of the 1918 influenza mostly died from secondary bacterial pneumonia, while victims of COVID-19 mostly died from an overactive immune response resulting in organ failure. The key major differences between the pandemics are highlighted in table 1 .

These comparisons are important to understanding and predicting the longterm effects of the new COVID-19 pandemic. The smaller number of deaths may be a result of our advances in the medical field over the century, such as diagnostic tools and extracorporeal membrane oxygenation machines.

By using synthetic biology, diagnosis could be done using full sequencing of COVID-19 strains, which would also reveal the number of strains. Additionally, obtaining data on patient genotypes would determine its impact on viral expression. Furthermore, vaccines developed with synthetic biology and then made with nanotechnology can be made in unlimited quantities compared with present methods of vaccine production, which use fertilised chicken eggs. Synthetic vaccines can be made to each strain with a unique sensor on each monoclonal antibody, which would indicate the presence of a particular strain, allowing efficient and timely vaccinations in each population.

We should also be able to begin to unravel the mystery of this virus. By studying each base of its positive-sense messenger RNA and determining its individual function, we can then predict patient prognosis and be better prepared to treat patients as they become ill. The prognosis of patients in the intensive care unit is currently poor, with high mortality rates and risk of permanent lung damage.

As we better understand the functional phenotypic expression of the COVID-19, we can start to predict the expression of viral mRNA and begin treatment earlier. This is a race between using our most advanced synthetic biology of the $21 \mathrm{st}$ century against a 21 st-century virus. We are 100 years away from 1918 and the tools that the scientists and clinicians had at their disposal in the last century. Let's hope that we can win this battle against this virus. It is difficult to predict how long this battle will continue but with synthetic biology in conjunction with social distancing, we should achieve victory.

Table 1 highlights the key differences between COVID-19 and the 1918 influenza.

Contributors STTL, LTL and JMR made substantial contributions to the conception or design of the work, the acquisition, analysis and interpretation of data for the work; drafting and revising the paper; final approval of the version to be published; and were accountable for all aspects of the work in ensuring that questions related to the accuracy or integrity of any part of the work are appropriately investigated and resolved. JMR lead the ideation and STTL did the majority of the data analysis and writing.

Funding The authors have not declared a specific grant for this research from any funding agency in the public, commercial or not-for-profit sectors.

\section{Competing interests None declared.}

Patient consent for publication Not required.

Provenance and peer review Not commissioned; externally peer reviewed.

\section{(2) OPEN ACCESS}

Open access This is an open access article distributed in accordance with the Creative Commons Attribution Non Commercial (CC BY-NC 4.0) license, which permits others to distribute, remix, adapt, build upon this work non-commercially, and license their derivative works on different terms, provided the original work is properly cited, appropriate credit is given, any changes made indicated, and the use is non-commercial. See: http:// creativecommons.org/licenses/by-nc/4.0/.

(c) Author(s) (or their employer(s)) 2021. Re-use permitted under CC BY-NC. No commercial re-use. See rights and permissions. Published by BMJ.

\section{D) Check for updates}

To cite Liang ST, Liang LT, Rosen JM. Postgrad Med J 2021;97:273-274.

Received 20 September 2020

Revised 25 November 2020

Accepted 29 November 2020

Published Online First 9 February 2021

Postgrad Med J 2021;97:273-274.

doi:10.1136/postgradmedj-2020-139070

\section{ORCID iD}

Shu Ting Liang http://orcid.org/0000-0002-5287-088X

\section{REFERENCES}

1 Bassareo PP, Melis MR, Marras S, et al. Learning from the past in the COVID-19 era: rediscovery of quarantine, previous pandemics, origin of hospitals and national healthcare systems, and ethics in medicine. Postgrad Med J 2020;96:633-8.

2 Barry JM. The great influenza. New York: Penguin Books, 2005.

3 Yang W, Petkova E, Shaman J. The 1918 influenza pandemic in New York City: age-specific timing, mortality, and transmission dynamics. Influenza Other Respir Viruses 2014;8:177-88.

4 Nunes B, Silva S, Rodrigues A, et al. The 1918-1919 influenza pandemic in Portugal: a regional analysis of death impact. Am J Epidemiol 2018;187:2541-9.

5 Worldometers. Coronavirus age, sex, demographics (COVID-19), 2020. Available: https://www. worldometers.info/coronavirus/coronavirus-age-sexdemographics/

6 McCarthy N. Infographic: which countries have escaped the coronavirus so far? 2020. Available: https://www.statista.com/chart/21279/countries-thathave-not-reported-coronavirus-cases/

7 D'Ambrosio A. Miscarriage and maternal mortality in pregnant COVID-19 patients, 2020. Available: https:// www.medpagetoday.com/infectiousdisease/covid19/ 86261

8 YCW, Ching-Sung C, Yu-Jiun C. The outbreak of COVID-19. Journal Of The Chinese Medical Association 2020;83:217-20.

9 Wu C, Chen X, Cai Y, et al. Risk factors associated with acute respiratory distress syndrome and death in patients with coronavirus disease 2019 pneumonia in Wuhan, China. JAMA Intern Med 2020;180:934.

10 Lopez-Rincon A, Alberto T, Lucero MM. A missense mutation in SARS-Cov-2 potentially differentiates between asymptomatic and symptomatic cases 2020 . 